\title{
OS(AS) APANHADORES(AS) DE FLORES E O PARQUE NACIONAL DAS SEMPRE-VIVAS: ENTRE IDEOLOGIAS E TERRITORIALIDADES
}

\section{Flower-picking and the Parque Nacional das Sempre-vivas: between ideologies and territorialities}

Fernanda Testa Monteiro

Mestre em Geografia

fernandamonteiro5@hotmail.com

Doralice Barros Pereira

Profa. Dra., Departamento de Geografia, UFMG pereiradb@yahoo.com.br

Rogata Soares Del Gaudio Professora Dra., Coltec-UFMG

Artigo recebido em 16/07/2012 e aceito para publicação em 13/08/2012

RESUMO: As dimensões ideológicas e suas articulações com natureza, comunidades, territorialidades e conflitos foram aqui privilegiadas. Identificamos visões sociais de mundo, expressas por meio das representações coletivas e de práticas circunscritas à apropriação do território em disputa, que aqui envolvem o Parque Nacional das Sempre-vivas, em Minas Gerais. A criação do parque desterritorializou comunidades apanhadoras de flores, que dependem dessas espécies para sobreviver. Sob a base de ideologias preservacionistas, o parque engendrou múltiplas invisibilidades. Os envolvidos, dentre eles os apanhadores, não se mantiveram refratários às ideologias, pressões e imposições; antes, potencializaram a realização política e de resistência.

Palavras-chave: Apanhadores de flores, Parque Nacional das Sempre-vivas, ideologias, territorialidades, conflitos.

ABSTRACT: The ideological dimensions and their respective interrelations with the environment, communities, territorialities and conflicts have been contemplated in this study. We have identified social views on world matters which were expressed collectively as well as practices within the appropriation of the territory under dispute, involving the Parque Nacional das Sempre-vivas (National Park of Strawflowers), in the State of Minas Gerais, Brazil. The creation of the park has deterritorialized flower-picking communities, whose means of support is this very activity. Under the basis of preservation ideologies, the park has brought about multiple invisibilities. The parties involved, including the flower-pickers, did not attain to the ideologies, pressure and constraints, but rather, allowed political and resistance issues to escalate. Keywords: Flower-pickers, Parque Nacional das Sempre-vivas, ideologies, territorialities, conflicts. 


\section{INTRODUÇÃO}

A história da humanidade é também a história de sua relação com o mundo material, significações atribuídas e formas de apropriação e uso. Martins (1996, p.15), dialogando com Lefebvre, parte do "núcleo explicativo do processo histórico - a relação entre o homem e a natureza -" e ressalta que o homem age sobre a natureza, na atividade social de atender suas próprias necessidades. Assim, o homem constrói relações sociais e concepções, ideias e interpretações, que dão sentido àquilo que faz e àquilo de que carece. Ele reproduz, mas também produz - isto é, revoluciona - a sociedade, base de sua atuação sobre a natureza, inclusive a própria natureza. Dessa forma, as concepções de natureza também se transformam ao longo do tempo, ou mesmo variam de uma sociedade/cultura para outra. Para Harvey (2011, p.75), a amplitude da categoria natureza está no fato de quase tudo abranger, inclusive a chamada "segunda natureza" produzida pelas atividades humanas, e "pouco pode ser imaginado como uma natureza pura e intocada, ausente de qualquer alteração humana".

A apropriação da natureza, do mundo material, por um certo grupo social dá-se a partir da sua interseção com um conjunto de valores culturais que definem e são definidos pelas práticas produtivas das diferentes formações sociais. A apropriação encerra desde a significação social dos recursos disponíveis - simbolização do ambiente de vida - até a práxis de manejo e formas não-convencionais de organização econômica. Assim, a organização cultural de uma formação socioeconômica é um tecido composto por valores, ideologias, sistemas de significação, práticas produtivas e estilos de vida, contextualizado geográfica e historicamente (LEFF, 2000, p.112). O modo de apropriação é, portanto, a "história social dos atos e processos humanos, no, sobre ou contra $\mathrm{o}$ mundo natural, (...) uma história dos homens com a natureza. Melhor ainda, uma história social passada entre os seres humanos e outros seres da natureza" (BRANDÃO, 1994, p. 27).

Com base nas relações sociedade/natureza/ cultura, analisamos as ideologias que ocultam/ explicitam proibições/interdições, configuram territorialidades e podem gerar disputas, conflitos e con- tradições; mas, também, resistência e lutas sociais, de que é exemplo o processo de criação e implantação do Parque Nacional (PARNA) Sempre-vivas. Num movimento dialético do pensamento, questiona-se: como se articulam territorialidades e ideologias, ou, como ideologias articulam territorialidades? É possível perceber distintas ideologias, a partir das práticas discursivas e políticas dos partícipes que ocupam lugares sociais diferentes nesse processo? Qual é o papel do Estado?

Na busca por compreensões, analisa-se o processo em torno do PARNA Sempre-vivas, situado na porção meridional da Serra do Espinhaço/MG. O parque criado em 2002, sem consulta pública, se sobrepõe a territórios sociais (LITTLE, 2002) de comunidades rurais extrativistas, que detêm relações ancestrais com o recorte espacial delimitado, associando-o ao vivido, às tradições, à produção da vida e da própria natureza. De um lado tem-se sujeitos cujas visões sociais de mundo advogam a proteção integral da natureza; de outro, os sujeitos cujas lutas resguardam seus lugares de vida, e, por fim, o modo como tais concepções interagem entre si.

\section{NATUREZA: ENTRE IDEOLOGIAS E TERRI- TORIALIDADES}

As ideologias são consideradas por Löwy (2002) visões sociais de mundo, conjuntos estruturados de valores, representações, ideias e orientações cognitivas. Para o autor, pode-se ter distintas visões sociais de mundo, ideológicas e utópicas, cada qual unificada em uma perspectiva social para cada uma das classes sociais que se enfrentam. Assim, o que existe não é uma ideologia dominante, mas sim enfrentamentos ideológicos, contradições entre ideologias, utopias ou visões sociais de mundo. Essas são, por sua vez, também conflitantes e contraditórias, porquanto calcadas na materialidade das relações capitalistas de (re)produção.

Para Therborn (1991), as ideologias incluem deliberadamente tanto noções e experiências cotidianas como elaboradas doutrinas intelectuais, e, ainda, a consciência dos atores sociais, de que são exemplos os sistemas de pensamento e os discursos institucionalizados de dada sociedade. As ideologias intervêm na 
formação e transformação da subjetividade humana, a qual se materializa em práticas sociais em um determinado contexto histórico - a nosso ver, territorial incluso. Quanto à análise de classe da dominação social, incide o papel desempenhado pela ideologia na dominação e luta de classes e a necessidade de se compreender sua função na organização, manutenção e transformação do poder na sociedade. Esse autor afirma que há ideologias de classes e ideologias que não são de classes ou por essas condicionadas.

As ideologias são complexos processos sociais de interpelação que mobilizam sentidos de reconhecimento e se dirigem aos sujeitos. Nesses processos contínuos, as ideologias superpõem-se, competem, chocam-se e se fundem, ou se reforçam. As interpelações ideológicas geram ou não ações responsivas de determinado sujeito a partir do contexto sócio-histórico de sua constituição ideológica (THERBORN, 1991). Nesse sentido, as ideologias "recrutam" todos que de alguma forma "aceitam" como evidente "o sentido daquilo que ouvem e dizem, lêem ou escrevem (ou do que tencionam dizer e do que se tenciona dizer a eles), na condição de sujeitos falantes" (PÊCHEUX, 1996, p.151).

Sem poderem ser teorizadas e analisadas apenas sob o ponto de vista político e econômico, as ideologias concernem também à cultura, à ciência, às artes e demais práticas de produção de significado. As práticas científicas, estéticas, filosóficas e legais são permeadas por ideologias. Mesmo que haja diferenças entre as dimensões de análise e seu conteúdo intrínseco, as práticas surgem de configurações ideológicas e podem funcionar como tal. Mas seu surgimento enquanto prática específica institucionalizada em uma divisão histórica de trabalho contribui também para a ruptura com as ideologias circundantes, mediante a produção de discursos específicos orientados a uma produção de consequências especiais e experiências cotidianas. A ciência, por exemplo, embora se apresente como um discurso particularmente objetivo, não permanece imune à subjetividade de quem a pratica, nem isenta de subjetividade os membros da sociedade. Também não se pode dizer que a ciência seja incapaz de afetar a subjetividade dos membros da sociedade, isto é, de funcionar como ideologia. Um exemplo é a obra de Darwin, que funcionou/funciona como ideologia - o darwinismo social (THERBORN, 1991).

As ideologias, compreendidas como representações coletivas manifestas nas práticas sociais, mediam/permeiam as formas de apropriação e uso do território. Enquanto representações contraditórias e em disputa procedem do vivido, do imediato pleno de singularidades e possibilidades. As representações não são simples fatos, nem resultados compreensíveis por sua causa, nem simples efeitos. Elas são, simultaneamente, falsas e verdadeiras: verdadeiras como respostas aos problemas reais e falsas ao dissimularem objetivos reais (LEFEBVRE, 1983). Toda realidade é mais rica do que a representação que dela se possa ter. Contudo, a representação deve ser entendida interligada às práticas sociais e ao contexto no qual se insere, num movimento em que Lefebvre a desloca para o âmbito da ação, tirando-a da esfera exclusiva do pensamento. Logo, práticas sociais expressam, refletem e refratam relações de poder, bem como aprendizados políticos e ações calcadas nas disputas territoriais.

Uma das formas perceptíveis das ideologias contida nas práticas sociais refere-se às práticas políticas (THERBORN, 1991), aqui captadas como ação coletiva (CHAUÍ, 2004). Já a ação popular equivaleria,

à ação de qualquer indivíduo do povo, do cidadão para defender bens públicos, contra atos ilegais do próprio Estado. Sempre que houver um ato ilegal praticado por autoridade pública e que comprometa a integridade do patrimônio público, caberá a ação do cidadão. Portanto, as condições da ação são a ilegalidade de um ato administrativo e sua lesividade ao patrimônio público. Os bens culturais foram equiparados, assim, aos bens públicos para virem a ter a proteção da Ação Popular (SOUZA FILHO, 1997, p. 58).

Ambas as ações, coletiva/popular, enquanto práticas sociais, dão-se no espaço. O espaço fragmentado é o locus da prática social, um produto social e histórico, político e ideológico (LEFEBVRE, 2008). A produção do espaço vincula-se a grupos que dele se apropriam para geri-lo a partir de normas, produzidas ao longo do tempo, que coadunam com representações 
povoadas por ideologia(s). Assim, as visões sociais de mundo acometem as identidades culturais dos sujeitos sociais desigualmente localizados nas sociedades de classe. Nesse contexto, os sentidos atribuídos à natureza traduzem-se em normas de apropriação e uso que incidem sobre a produção do espaço, definindo, por exemplo, fragmentos a serem "protegidos da ação humana" tornando-se "intocados". Se considerarmos os múltiplos sujeitos sociais, suas visões sociais de mundo acerca da natureza e do meio ambiente podem abarcar dissonâncias, concorrenciais e conflitivas, permeadas pelas ideologias. No caso que envolve o PARNA Sempre-vivas, tais repercussões expuseram que:

Meio ambiente é a questão da preservação com o ambiente natural. É o ambiente natural que a gente tem. Eu percebi que eu tinha uma ligação com a área de meio ambiente, que tinha uma ideologia maior. Tem que preservar um lugar [natural] que você possa olhar. Já tem tanta coisa antropizada, que você precisa dessa área prá você se refugiar (Técnico gestor do PARNA Sempre-vivas, entrevista em janeiro de 2010).

A natureza sou eu, você, os bichos, o mato, os rios... é a natureza. Meio ambiente? É aquele pessoal que chegou aí, eles ficam lá na casa da Kolping [local utilizado pela equipe gestora do PARNA Sempre-Vivas no interior da unidade] (Moradora de comunidade atingida pelo parque, declaração em fevereiro de 2010).

A natureza e o meio ambiente são posicionados no centro da luta ideológica, ao oporem os sujeitos, suas concepções e práticas face ao parque. Quando um interlocutor reconhece que "a natureza sou eu, você, os bichos, o mato, os rios...", o faz numa perspectiva integradora à natureza, na qual o humano se reconhece também como natureza, incluída, portanto, ao seu ser. Todavia, quando outro sujeito afirma que "já tem tanta coisa antropizada, que você precisa dessa área pra você se refugiar" denota, no plano discursivo e ideológico (BAKHTIN, 1992), a palavra como o signo ideológico por excelência, o afastamento entre homem e natureza, ou seja, a externalidade dessa relação. Além disso, demarca ser "você" e não "eu” quem precisa "da natureza" para se refugiar. Bem como cabe indagar de quem ou do que é necessário se refugiar. Assim, as concepções de natureza contêm formas de organização social no território, com afirmações/sanções (THERBORN, 1991) traduzidas em normas de sua apropriação e uso; ao mesmo tempo, dialeticamente, ordenam-se matrizes de submissão/ qualificação dos sujeitos interpelados de distintos modos e em amplas dimensões da subjetividade humana. Elas confrontam, num mesmo recorte espacial, lutas sociais afeitas às novas territorialidades, ilustradas a seguir:

Nós temos que proteger a natureza. Porque, caso contrário, corremos o risco de desaparecer junto com ela. Dependemos dela e não podemos destrui-la. Por isso, os parques são muito importantes. (...) Eu me realizo nesse trabalho porque sinto que estou contribuindo, pelo menos um pouco, com o planeta, contra a destruição causada pelo homem. Se continuar no ritmo que está, não vai sobrar nada e a humanidade vai sofrer as consequências (Técnica gestora do PARNA Sempre-vivas, entrevista em dezembro de 2009).

Pra que, que eles [órgãos ambientais] fazem parque? Eu não entendo essa coisa. Por acaso é prá soltar bichos lá dentro, tipo cobra ou onça que eles acharem por aí? Porque prá gente que depende dessa área prá viver, é que não é. E preservado já estava porque nós preservamos. Eles não fizeram nada, já acharam essa região com a natureza cuidada por nós. Mas eles acham que a gente não sabe nada e falam que destruimos a natureza (Apanhadora de flores sempre-vivas, declaração em julho de 2009).

A imagem do parque nacional e de outras áreas protegidas como um paraíso onde a "natureza virgem" se manifesta em toda sua beleza relança o debate sobre mitos e simbologias nas sociedades modernas (DIEGUES, 2001), reelabora crenças antigas e incorpora elementos da ciência moderna. A materialização histórica do preservacionismo, ou o "culto ao silvestre" (ALIER, 2007) através da criação de parques, dá-se 
em especial em ex-colônias européias tropicais, em áreas rurais ocupadas por indígenas e comunidades tradicionais camponesas. Tais grupos, portadores de outros mitos e signos relativos à natureza, sustentam outras visões sociais de mundo e de formas de com ela se relacionar, não reconhecendo a dicotomia sociedade/natureza. É nesse contexto que defensores da proteção integral da natureza e comunidades locais adensam as disputas territoriais, que marcam a segunda metade do século XX.

A criação de "áreas naturais protegidas" tornou-se um dos marcos da temática ambiental na modernidade, entre elas as UCs. Forjadas no imaginário urbano, tendo como referência a dicotomia sociedade/natureza, aparecem, em especial, as unidades de conservação de proteção integral, que demandam a retirada de antigos moradores de seu interior ou mesmo os negligencia em prol da preservação da natureza "pura e selvagem". Proposição de forte referência eurocentrada, remete à natureza intocada, ou a torna intocável, onde o homem lhe é exterior. Essa concepção de natureza indefesa e ao mesmo tempo um recurso a ser compreendido/explorado foi aprofundada pela sociedade urbano-industrial-capitalista (MONTEIRO, 2011).

Tais UCs, materializadas sobretudo em espaços rurais em países em desenvolvimento, sobrepõem-se a territórios materiais e imateriais (HAESBAERT, 2007) constituídos historicamente pelos que ali habitam. O rural constitui uma categoria político-ideológica e transacional que faculta a compreensão e a construção de uma representação social em torno do espaço e do tempo (WANDERLEY, 2001). A ruralidade revalida a cultura, as práticas, a construção imaginário-simbólica e ressignifica o espaço, salientando lugares que remetem a um modo de vida singular. A interação de relações, processos e práticas constituem tentativas concretas de produção e reprodução de espaços como formas de resistência ou de re-existência (DAMIANI, 2001, p.54).

No Brasil, a criação do Sistema Nacional de Unidades de Conservação da Natureza (SNUC), em 2000, inspirou-se na proposição da União Internacional para a Conservação da Natureza, apoiada no preservacionismo estadunidense. Uma das inovações do SNUC foi a de instituir a obrigatoriedade da realização de consulta pública com os moradores locais para a criação de UCs. Ela visou evitar a insurgência e/ou recorrência de conflitos com processos tumultuados de criação e implantação, como ocorridos em parques nacionais e estaduais, de que são exemplos, o Parque Nacional Cavernas do Peruaçu (MUNGAI, 2008) e o Parque Estadual de Ibitipoca (BEDIM, 2008), localizados em Minas Gerais.

A criação de unidades de conservação de proteção integral em áreas habitadas acirra conflitos e ao mesmo tempo são vinculadas, atualmente, à rota dos processos de compensação ambiental. Esse é um arranjo do qual se valem algumas empresas para, através da criação dessas unidades ou de investimentos em seus projetos (implantação, manejo e gestão, de sinalização, etc.), (re)compensarem a degradação/ prejuízo causados por suas atividades ou produtos em outro local - a exemplo da Fiat com o PARNA Cavernas do Peruaçu (MUNGAI, 2008). A moderna necessidade de criação das UCs de proteção integral sustenta-se também nos serviços ambientais, como o suprimento de água, ar puro, etc., para a sociedade urbano-industrial-capitalista. Práticas do turismo e à manutenção da biodiversidade para pesquisas científicas têm nos parques áreas estratégicas para o desenvolvimento e permanência de suas atividades. Já os governos estaduais e o federal vêem na criação de parques um mecanismo para cumprir de metas da agenda ambiental global referente à adequação ambiental, daí a defesa de aumento dessas UCs - de que é exemplo a criação do PARNA Sempre-vivas.

De múltiplos lugares sociais emergem discursos ecológico-ambientais cujas práticas contraditórias colidem com significados acerca da sustentabilidade. Ambientalistas, chefes de Estados, representantes privados, técnicos governamentais e não-governamentais, educadores, entre outros, propagam uma responsabilidade indistinta pela crise ambiental e por sua reversão. Não se trata de um discurso uníssono, mas hegemônico, de categorias também hegemônicas do pensamento moderno, para legitimar-se socialmente, chegando aos mais recônditos lugares - apresentando-se, portanto, como inegável e inevitável. A partir dos discursos de proteção da biodiversidade e do desenvolvimento sustentável, justificam-se e se legitimam uma certa apropriação, uso e controle territorial. 
Ao interpelar a "todos" como responsáveis pela "crise ambiental e por sua reversão", com base num "futuro em comum", incute-se no imaginário coletivo a ideia de que todos participam de uma comunidade imaginada (ANDERSON, 1991), de escala global. Sem discernir as forças e formas de consumo da natureza, universalizam-se responsabilidades e a questão ambiental passa a ser descolada da relação sociedade/natureza mediada pelas técnicas para uma relação onde se toma a causa pelo efeito sem se questionar a produção da crise e as desigualdades e contradições que a compõem. A universalização é, pois, um dos modos de se operar as ideologias (THOMPSON, 1989) e, nesse contexto, despolitiza-se a questão ambiental, tendo os Estados Nacionais, apoiados na/pela ciência moderna, papel fundamental.

A ecologia científica, ao articular conhecimento e poder (CHAUÍ, 1982), é postada como verdade na modernidade e tende-se a racionalizar o território independentemente das paixões e interesses envolvidos, o que acaba por legitimar as políticas governamentais adotadas (ACSELRAD, 2004). Há que se compreender a ciência moderna como processo social histórico e não como uma entidade dada (FOLADORI e TAKS, 2004). A ciência moderna impõe mudanças nas relações sociais, embora "as pessoas tendam a agir de acordo com suas expectativas, crenças e compreensão do mundo" (HARVEY, 2011, p. 103).

Torna-se fundamental precisar a participação ativa dos sujeitos no exercício político que lhes permita definir e nomear o que vivenciam em/de seus lugares. Nesse exercício, é imprescindível o reconhecimento das fronteiras que opõem esses grupos aos sujeitos e projetos que lhes são antagônicos quanto às suas perspectivas e expectativas de apropriação e uso do território. Mendes (2009) enfatiza que o deslocamento do passado para o presente incrementa a interlocução e a ação como centrais na criação e manutenção de UCs, uma vez que à cena comparecem cidadãos-coletivos defensores de uma atribuição justa e diferenciada de direitos, a exemplo dos(das) apanhadores(as) de flores.

A legitimação desses grupos como interlocutores, no processo decisório das políticas públicas, torna possível o diálogo e a abertura à participação social (MENDES, 2009, p. 240-241), assim como os coloca na condição de sujeitos de direitos, entre os quais, o direito à vida e ao território. Nessa perspectiva, formas de apropriação material e simbólica do espaço divergentes das dominantes são admitidas, mesmo que sua materialidade seja perpassada por ideologias e disputas que se desgastam em assimetrias de poder procedentes do processo sócio-histórico de subalternização/colonização.

\section{IDEOLOGIAS E TERRITORIALIDADES EM CONFLITO - UM OLHAR SOBRE O PARQUE NACIONAL DAS SEMPRE-VIVAS}

\author{
"Esse lugar nasceu pra ser parque. Tinha que \\ virar parque" (Membro de ONG). \\ "O que eu mais escuto na comunidade quando \\ alguém fala do parque é assim: \\ eu perdi a minha liberdade" (Morador de \\ comunidade atingida pelo PARNA Sempre- \\ -vivas).
}

A dicotomia sociedade/natureza pode ser rompida ao se ter em conta que o espaço é social e é natureza, um tema necessariamente político. Há interdependência e inseparabilidade entre a materialidade, que inclui a natureza e o seu uso, e a ação humana e política (SANTOS, 2002). O espaço, em decorrência da utilização e da natureza do uso, transforma-se em território (HISSA, 2009), inclui vários atores sociais e é objeto de análise social. Assim, o território é a categoria aqui privilegiada, um corpo social espacializado procedente da utilização do espaço como híbrido, detentor de limites e fronteiras, com significados contraditórios. É um recorte sempre incompleto da totalidade que se transforma a partir da referência da totalização.

O espaço poderia ser concebido, em certos contextos, como imaterialidade, a partir do cruzamento entre o percebido das representações do espaço e o vivido-simbólico dos espaços de representação (na linguagem lefebvriana). O território, focado na dimensão política do espaço, imbricado das relações de poder, exige o momentum da materialização através de uma prática social (HAESBAERT, 2009, p. 104-105). A prioridade, ou mesmo as decisões sobre os usos e destino de um território, responde também às distintas 
visões sociais de mundo e expressam práticas sociais, materializando-se dialeticamente no espaço-tempo, o que pode ser observado no processo de criação do parque em questão. $\mathrm{O}$ choque entre uso e apropriação traz as UCs de proteção integral como simulacros de território, simulados para a preservação/proteção, que negligencia as necessidades locais, em especial aquelas fora do preestabelecido - ao circunscrito enquanto "parque".

O Estado é responsável pela criação e delimitação das UCs, processo que é pautado por instituições nacionais e internacionais (governamentais e não-governamentais), que declaram a importância da preservação dos recursos naturais e, por conseguinte, de se criar, implantar e assegurar leis ambientais baseadas em critérios científicos. Os cientistas alinhados a tal visão social de mundo, ao justificarem que certo espaço ou bioma merece ser protegido da ação humana, e, portanto, controlado pelo Estado, cujas forças repressoras podem garantir essa proteção, se necessário, legitimam a dicotomia sociedade/natureza.

Em fins de 1990, a Serra do Espinhaço, em Minas Gerais, foi avaliada como "área prioritária para a conservação/proteção da biodiversidade" por gestores ambientais públicos, técnicos de organizações não-governamentais ambientalistas e cientistas. Essa avaliação foi ratificada no Zoneamento Ecológico Econômico de Minas Gerais, que elegeu a criação de UCs de proteção integral da natureza como política ambiental oficial. As justificativas, discursivamente, permearam-se em favor das espécies endêmicas da flora nativa - como as flores sempre-vivas, algumas raras e "ameaçadas de extinção" -, das suas "novas" raridades (LEFEBVRE, 1969); do ar e água de qualidade da abundância de água; da beleza cênica exclusiva a ser contemplada/reverenciada; da importância de áreas para a execução de pesquisas científicas para melhor se conhecer o bioma/biodiversidade; e de atividades turísticas, vetor de "desenvolvimento regional sustentável", com destaque para o ecoturismo.

Seguindo essas prerrogativas, o PARNA Sempre-vivas foi criado através do decreto sem número em 13/12/2002, mas sem efetuar a consulta pública, que é uma exigência da lei desde 2000. O parque localiza-se no que Saadi (1995) define como planalto meridional da porção mineira da Serra do Espinhaço e cobre quatro municípios: Diamantina, Buenópolis, Bocaiúva e Olhos D'água. Possui cerca de 124.000 ha, que, até o presente momento, estão sem plano de manejo e regularização fundiária.

$\mathrm{O}$ alinhamento das concepções e interesses, no campo (BOURDIEU, 2009) ambiental, acionou os elementos água, paisagem e espécies vegetais exclusivas e em extinção como eficientes mobilizadores de sentidos pelos sujeitos ocupantes de cargos/posições institucionais diferentes. As concepções atenderam tanto às demandas do governo federal voltadas ao cumprimento de uma ordem ambiental global, quanto àquelas do movimento ambientalista "mineiro", para a criação de UCs de proteção integral, e, ainda, aos políticos locais, na auferição de rendas tributárias. Desse "consenso" pré-construído entre escalas estatais de poder - diretamente entre o local e o federal - conferiu-se legitimidade à proposta. Um dos fundadores de uma organização não-governamental ambientalista e consultor na criação de UCs em Minas Gerais anuncia como motivador para o parque:

O grande mote foi a proteção da biodiversidade, claro que passando aí pelo viés econômico da utilização turística. [...] É uma área que ainda tem manchas de vegetação significativa, espécies endêmicas que já estão raras. $A$ fauna super expressiva, a gente tem espécies ameaçadas lá. (...) Nós achamos que o parque [...] tem que ter uma utilização turística razoável, até mesmo para que se tenha a base política prá criar novos parques. Se você não tem um uso destinado à população que seja importante prá ela, que tenha retorno em termos de uso, recreação, você não consegue a mobilização da sociedade prá criação de novos parques (Consultor do IBAMA, entrevista em setembro de 2010).

Do fragmento discursivo, a articulação e as conexões entre grupos e interesses reconhece-os como estratégicos na efetivação de práticas já normatizadas pelo Estado. É evidenciado, ainda, a corporeidade territorial feita de uma rede assimétrica de poder construída ao longo da história - produto ela mesma 
de conexões assimétricas e desiguais entre os lugares. Há, ainda, no plano discursivo, a inseparabilidade entre território e lugar na atualidade:

O que buscamos fazer foi obter o máximo possivel de representação de ambientes, assegurando os maiores e os melhores remanescentes de vegetação nativa. E de outro lado, a redução de impactos sociais. No meu ambiente de trabalho, eu tenho sempre isso, essa postura de tentar reduzir, recortando o máximo possivel os limites, prá reduzir os impactos sociais [que] são decorrentes de desapropriações, envolvimento de terras produtivas. Prá isso, busco não pegar fazendas bem instaladas, montadas. Uso carta topográfica, imagem de satélite e visita de campo, os três, prá fazer esse trabalho da limitação. (...) Na área, eram poucas, área de alto de serra, não tinha fazenda significativa. (...) A gente procurou limitar as áreas sem nenhuma relevância econômica (Consultor do IBAMA, entrevista em setembro de 2010).

Esse trecho traz à tona um dos significados atribuídos a "terras produtivas" no fundamento de lógicas e índices modernos de produtividade, apoiados no conhecimento técnico-científico, ou seja, de empreendimentos "bem instalados". Tal concepção autoriza certos atores, mais "aptos" e "competentes", a permanecerem em seus lugares, ao mesmo tempo em que deslegitima outros atores, aqui referente à apropriação tradicional camponesa. A distribuição diferenciada dos poderes materiais e simbólicos em jogo traduz potenciais desiguais para a posse, uso e controle do território. O Estado-Nação e a ciência moderna, nos quais as ONGs e os órgãos ambientais se apoiam, integram uma luta classificatória pela representação legítima da natureza e seus usos "adequados", redistribuindo poder sobre os recursos territorializados.

Após o estudo para a criação do parque, a proposta foi encaminhada aos analistas do IBAMA à época, e direcionada à revisão, que pautou a ampliação sua extensão "pela necessidade de se proteger maior área possível do Espinhaço", conforme o "Atlas" de áreas prioritárias de proteção/conservação da biodiversidade em Minas Gerais. Esse parecer preconizava que a escolha e o tamanho da área deveriam privilegiar os "objetivos nacionais de conservação da natureza". Simultaneamente, questionavam os "impactos sociais", pois carecia-se de "um fator de análise que avalie se o desenho do limite proposto para a unidade é adequado para garantir a efetiva proteção das amostras de ecossistemas abrangidos pela unidade contra pressões e alterações advindas dos usos e manejos das áreas vizinhas" e defendia a ampliação para a sobrevivência dos animais identificados nos relatos. E, ainda, a sua criação "fortaleceria economicamente a atividade turística, evitando o êxodo rural" (IBAMA, 2002, p.123-125).

Nesses termos, justifica-se que alguns devam ser "sacrificados pelo interesse maior" - da comunidade nacional - de proteção da natureza, deslocalizando compulsoriamente determinados grupos para a localização de outros. Todos esses elementos corroboram a força do preservacionismo apoiado na ciência da conservação e permeado por ideologias relativas às dimensões existencial, inclusiva, posicional e histórica (THERBORN, 1991), que é exemplificada pela passagem a seguir:

Sobrevoamos a região com helicóptero, porque facilita o trabalho, e não tinha moradores na serra, casas na área. (...) Aí chamou a atenção umas formações de quartzito muito bonitas, muito campo bonito e serra. Aquele ambiente de serraria bonito! (...) E muita região de campo também, assim mais pro sul, tava bem conservada. (...) No [PARNA] Sempre-vivas tinha muita água, tinha que proteger isso! (...) Pegamos os pontos de GPS, tendo como base os limites naturais como paredões e cursos d'água para ficar claro onde eram as divisas. E deixamos as comunidades fora do parque (Técnico do IBAMA, entrevista em fevereiro de 2010).

A defesa dessa ordem, através de códigos normatizados, afirma/sanciona certos aspectos da realidade e silencia outros, em favor do ordenamento territorial. O sobrevôo, por exemplo, permitiu a visualização dos atributos físicos/geográficos da paisagem claramente admirados e valorizados pelo entrevistado. 
O “olhar do alto" propiciou uma percepção espacial, de ampliação idealizada do parque, que valeu-se dos acidentes geográficos e recursos naturais. Nessa escala - do alto - é impossível apreender os processos sociais que se sucedem na dinâmica territorial do "chão de mundo". Ainda que existissem informações da coleta de flores e criação de gado pelas comunidades rurais, esse lugar de enunciação foi reiteradamente negado quando da criação do parque. O novo perímetro bordejou comunidades, priorizou o aparente "vazio demográfico" e a natureza "intocada" de grande beleza cênica e deixou "de fora" aqueles que têm a serra como lugar de vida - os territórios sociais de comunidades rurais locais. Silenciaram-se/ocultaram-se conflitos e contradições, reforçados à medida que o planejamento e a materialização do parque consolidaram práticas excludentes abarcando maior perímetro e excluindo pessoas e modos de vida.

No segundo semestre de 2002, ocorreu outro momento emblemático na criação do parque, quando uma consulta sobre a nova proposta foi disponibilizada por meio de publicação no Diário Oficial da União e na página do IBAMA, na internet, durante 15 dias, para manifestações populares. Dos três registros, um indagava sobre a realização de audiência pública no local, sobre os limites do parque e a indenização das terras; outro questionava a escolha da categoria parque ao invés de reserva extrativista, por ser uma região de comunidades extrativistas de flores sempre-vivas. Somente a segunda obteve resposta, de que "não haveria consulta pública" e as dúvidas sobre a regularização fundiária poderiam ser esclarecidas junto ao IBAMA (IBAMA, 2002, p.145-151). No mês seguinte, um despacho da Coordenação Geral de Conservação de Ecossistemas do IBAMA declarou que a área tinha "rarefeita ocupação humana, solos pobres com grande limitação para qualquer tipo de uso econômico, baixo preço das terras e processo de degradação ambiental". A importância biológica da região foi ratificada e a "consulta pública" concluída com apenas três manifestações, "sem nenhuma proposta concreta de modificação dos limites do parque". Ressaltava que, anteriormente, reuniões públicas a respeito da criação do parque já haviam sido promovidas, inclusive com apoio local (IBAMA, 2002, p.147). Tão logo a consulta feita pela internet foi validada pelos procu- radores do órgão, o decreto foi assinado e publicado, em dezembro daquele ano, criando-se oficialmente o PARNA das Sempre-vivas (IBAMA, 2002).

As estratégias para cumprir a exigência da "consulta pública" passaram pelo conhecimento, enquanto poder que determinados sujeitos adquirem, devido aos lugares sociais que ocupam (técnicos e dirigentes políticos), como também pela destituição dos moradores locais de informações/formações. Para Bourdieu (2009), o Estado é detentor do monopólio da violência simbólica legítima. Como assinalou Thompson (1989), a dominação passa por relações sistematicamente assimétricas, nas quais grupos particulares de agentes detêm o poder, de maneira permanente e em grau significativo, permanecendo tal poder inacessível a outros grupos de agentes, independentemente da base sobre a qual tal exclusão é levada a efeito.

Os reflexos da ação governamental afloraram nas interlocuções com os moradores de variados lugares sociais de toda a área ampliada. A maioria deles não sabia explicar o processo de criação do parque e indicavam o ano de 2007, quando "o tal do meio ambiente chegou na serra e proibiu a gente de tudo", nos seus dizeres. Os que vivem nas comunidades rurais reiteram não identificar quando e como foi criada a unidade, seu tamanho, limites e mesmo o significado de proteção integral da natureza. Desconhecem o Diário Oficial da União, algumas das comunidades atingidas não têm acesso à energia elétrica, além do raro acesso à internet, de forma que foram cerceados de intervir nas decisões.

O Estado, alçado à instância do saber-poder, é aquele que pode, legitimamente, decidir sobre a criação de áreas de proteção. Embora o PARNA Sempre-vivas tenha sido criado após o SNUC (2000), as exigências legais foram insuficientes e ele foi imposto à revelia do lugar. Constata-se assim, a permanência das práticas estatais autoritárias e a fragilidade da Lei, limitada à letra e não à prática. Ao mesmo tempo em que perpetua, nos órgãos públicos, uma prática institucional consolidada na ditadura militar, refletindo o habitus (BOURDIEU, 2009) de sujeitos, os quais compartilham uma visão social de mundo balizada na dicotomia sociedade/natureza e de negligência aos direitos das comunidades locais.

Toda ação política contém um caráter simbólico e todas as atividades humanas detêm uma 
base territorial (CLAVAL, 1973). A multidimensionalidade do "vivido territorial" pelos membros de uma coletividade é refletida pela territorialidade (RAFFESTIN, 1983). De um lado, os movimentos de apropriação, dominação e resistência em um dado território contrapõem-se aos de submissão, emigração e desapropriação; por outro, traduzem desencontros e simultaneidades (CAMPOS e KRAHL, 2006). A territorialidade deriva de ações sociais e de concepções de domínio e uso, de uma construção de vínculos cujo objeto é dominar uma extensão ou dela participar. Os vínculos territoriais dependem da relação com os vários âmbitos da integração socioespacial (HEIDRICH, 2009).

Uma vez decretada a criação da unidade, o IBAMA, entre 2004 e 2007, e o Instituto Chico Mendes de Conservação da Biodiversidade (ICMBio) a partir de 2007, procederam a implantação do parque. Processo este marcado por conflitos que externalizam contradições atinentes aos silenciamentos produzidos, como o argumento do "vazio demográfico", gerador de conflitos entre territorialidades sobrepostas; a estrutura fundiária, enquanto processo histórico; e as subjetividades em meio às normas objetivadas de apropriação, uso e controle espacial, em que os gestores visavam à territorialização da unidade e consequente desterritorialização dos camponeses/coletores de sempre-vivas.

As estratégias iniciais de materialização da unidade, enquanto práticas políticas, utilizadas pelos gestores do IBAMA, incluíram o contato inicial com moradores locais para comunicar a existência da unidade e as mudanças nos usos da área; o levantamento dos proprietários de terras e a localização das fazendas e posses; o levantamento de informações cartográficas e a sinalização de alguns dos pontos limítrofes do parque ainda não demarcados oficialmente; o combate ao uso do fogo, com a formação de brigadas e de "campanha de conscientização" na rádio local; a confecção de um termo de cessão de uso da área sob domínio de uma organização da igreja católica, tornando-a a base do órgão no parque; e a implantação de um sistema de rádio, adquirido via compensação ambiental, para comunicação entre os vigilantes contratados e o escritório da unidade sediado na cidade de Diamantina.

A chegada da equipe do ICMBio, a partir de 2007, modificou o significado do parque ao serem intensificados os cerceamentos das práticas vivenciadas pela maioria dos moradores locais - "foi quando o parque chegou", nos dizeres locais. As ações voltaram-se aos avisos aos moradores quanto às atividades interditadas no parque; à fixação de placas de sinalização assinadas pelo ICMBio; às exigências de cumprimento da lei no exercício das atividades no entorno da unidade; às ações de fiscalização, contando com helicópteros e policiais federais, e aplicação de multas, além das prisões de moradores dentro e no entorno do parque; à destruição de ranchos dos moradores locais localizados no interior do parque; e à constituição do conselho consultivo da unidade agregando atores sociais diversos.

Os técnicos classificaram as atividades efetuadas no interior da unidade pelas comunidades locais, a exemplo da criação de bovinos, do uso do fogo voltado à renovação de pastagens nativas e da coleta de flores, como "ameaças à conservação da unidade". As travessias, feitas pelos moradores a cavalo, de uma comunidade a outra dentro do parque, também foi decretada como "ameaça", ainda que circunscritas aos caminhos/estradas de uso secular. Já na zona de amortecimento/entorno da unidade, também fiscalizada, as "ameaças" incluíam o garimpo artesanal (próximo à Diamantina) e a supressão de vegetação nativa, mesmo em áreas destinadas a cultivos familiares nas cotas mais baixas e úmidas. Um desafio apontado pelos técnicos na implantação efetiva do parque foi a ausência de regularização fundiária, sem previsão de orçamento ou data para acontecer, embora simultaneamente denunciassem a situação irregular das propriedades e posses - processo sócio-histórico.

O uso de categorias hegemônicas, científicas e jurídico-políticas, alçado a um pensamento moderno ocidental acerca da natureza (SOUSA SANTOS, 2010), e mecanismos de ação justificada pela atuação do Estado - e seus representantes - concentraram poder de controle sobre os recursos, sujeitos e ações na área delimitada. Mecanismos de submissão, assentados na tecnologia, no medo, na exclusão tecnológica e discursiva e no uso legítimo da força física pelo Estado e seus representantes (WEBER, 2005) prenunciam:

Eles têm lei, avião, fala dificil e usa arma. Nós não (Morador atingido pelo PARNA Sempre- 
-vivas, entrevista em fevereiro de 2010).

Tenho medo dela [a gerente] me prender sozinho, andando pela serra, e me levar prá uma cadeia longe e ninguém ficar sabendo. Aí como é que faz? (Morador atingido pelo PARNA Sempre-vivas, entrevista em fevereiro de 2010).

Na medida em que o outro não se reconhece/ atende a uma interpelação, neste caso preservacionista, um choque se instala face às novas normas de uso dos territórios. A imposição da proteção integral processa-se em uma correlação assimétrica de poder, que, na defesa de uma ordem com afirmações e sanções (THERBORN, 1991), atrela tensões repletas de subjetividades reprodutoras das contradições sociais. Essas, embora tenham sido percebidas e interpelem o Outro, foram incapazes de inflectir nas práticas institucionais:

A fiscalização étensa, no início. Por mais que seja necessário uma certa educação, e, obviamente, sempre o respeito pela pessoa, você tá questionando ou mesmo indo multar ou coisa assim. Infelizmente você pega sempre gente de pequeno porte, você não pega aquele infrator realmente que fez um desastre, aquele imenso lá com máquinas e gente trabalhando. [...] Mas você pega pessoas menores. Que não têm uma renda muito boa, que usam geralmente o fogo por causa do gado que é a renda familiar dele. Ou por causa das sempre- vivas porque pega prá coleta prá família também. Então essa coisa de sempre pegar, na maior parte das vezes, essas pessoas menos favorecidas, com a renda mais baixa, eu não gosto, eu não acho legal multar. Mas é a minha obrigação e é o que a legislação manda. O lado bom é você pegar esses atos. A gente tá aqui prá proteção, principalmente, então você impedir ou conseguir pegar uma coisa irregular, prá mim é maravilhoso, porque eu estou fazendo o meu trabalho. Infelizmente é isso, eu não posso fazer nada (Técnico do ICMBio, entrevista em dezembro de 2009).

Os conflitos entre órgãos ambientais e comunidades eclodiram em 2007 após a proibição do uso das principais áreas de coleta de flores no interior do parque. As territorialidades (HEIDRICH, 2009) dos camponeses combinam estratégias de vida e saberes complexos, plenos de significações e compreensões nesses lugares, cujos saberes geográficos (CLAVAL, 2009) foram transmitidos e reinventados ao longo de gerações. A organização do trabalho, de natureza familiar, para o autossustento, e a renda advinda da comercialização do que produzem, acionam códigos de apropriação e uso da terra em que as relações de parentesco são marcantes. As representações e práticas sociais com o ambiente possibilitam aos apanhadores compreender a natureza como criadora da vida e como um todo do qual fazem parte.

Para os moradores, ir aos campos, concebidos como áreas de uso comum, para "panhá flor" (nos dizeres nativos), refunda sentidos para além do econômico. As comunidades ouvidas qualificam a serra e os campos quanto à ancestralidade, afetividade, prazer, liberdade, trabalho, renda e tradição. As "flores sempre-vivas" - plantas cujas principais espécies comercializadas pertencem aos gêneros Comanthera e Syngonanthus - nascem nos campos rupestres do cerrado e se referem, popularmente, às inflorescências colhidas e secas que conservam sua forma e coloração por longo período após a coleta. Além das flores, também são coletadas folhas, frutos secos, cipós, algumas sementes, etc., a depender da época do ano e demanda. A abundância de água na região é, para os moradores, importante riqueza, um patrimônio herdado. Os usos combinados dos diferentes agroambientes, com saberes tradicionais associados, rendem o sustento das famílias. E a pluralidade de atividades confere maior flexibilidade perante os contextos internos e externos à família.

É na relação estabelecida com esse recorte espacial que vínculos identitários (HEIDRICH, 2009) emergem nas expressões nativas: "desde que eu me entendo por gente, sou panhadora de flor" e ainda "esse é nosso ofício, tenho orgulho disso". A identidade territorial diz respeito a uma experiência histórico-geográfica comum, expressa elos entre o ator e o espaço (idem, 2009) e se revela na relação com o Outro. Um discurso que reivindica direitos historicamente negados e busca legitimidade na manutenção do território, que aporta sentidos de modos de vida 
calçados na ancestralidade, "tradição" - reelaborada e ressignificada no presente - e "cultura" que constituem a comunidade que por elas se pauta (CUNHA, 1985).

A coleta das flores sempre-vivas, parte fundadora dessa cosmologia, é reconhecida como importante para centenas de famílias na região de Diamantina. Não obstante, baseados em critérios técnico-científicos, os órgãos ambientais oficiais afirmam que a pressão e coleta inadequada geram a extinção de algumas espécies (IBAMA, 2002). O universo de espécies vegetais coletadas, em comunidades de 58 municípios da região, é superior a 200. Para alguns pesquisadores, a precisão da lista das espécies ameaçadas de extinção pode não corresponder à realidade ali observada (UFV JM et al., 2009). Para os apanhadores, o sentido atribuído às flores aproxima-se a dádiva ofertada por Deus para que possam viver:

Deus deixou as flores pro povo ter renda. Muita gente já cuidou da família com renda das flores. Eles [órgãos ambientais governamentais] não deixam mais panhá flor. E o castigo deles é que nem eles, nem nós, vamos ter as flores. Porque elas não dão sem a mão do homem (Apanhadora de flores sempre-vivas, declaração em julho de 2009).

Ambas as visões, a de "culto ao silvestre" e a das comunidades locais, podem acionar o discurso sagrado, apelar para valores culturais antigos e repudiar a proeminência do valor econômico, aproximando-os e favorecendo alianças contra a exploração capitalista da natureza (ALIER, 2007). Nessas visões, uma dimensão afetiva em relação aos animais, plantas e à própria Terra, aproxima e até propicia uma interação ideológica. Todavia, outras significações atravessam suas visões, bem como o lugar social de onde experimentam o mundo, gerando desencontros e disputas territoriais quando da implantação de UCs de proteção integral sobrepostas a territórios sociais.

Para assegurar a necessidade da categoria parque, os sujeitos locais foram transferidos da condição de coletores para a de degradadores, ainda que esses ambientes fossem avaliados como suficientemente conservados para fins de preservação/proteção. Há um duplo e contraditório movimento que legitima a dicotomia sociedade/natureza e deslegitima a condição de "apanhador de flores", de um dia para o outro, desterritorializando esses grupos.

Em ação responsiva, em 2007, os(as) apanhadores(as), em manifestação pelas ruas de Diamantina/MG, reclamaram que fossem ouvidos e que a proibição da coleta fosse discutida, quiçá revogada. Em 2009, durante um debate público, os moradores das comunidades reivindicaram o direito de acesso aos campos para garantir a sobrevivência de suas famílias, Eles alegaram dificuldades econômicas em virtude da criação do parque e da fiscalização ambiental severa, muitas vezes hostil, praticada pelos gestores da unidade, que criminalizam as atividades das quais dependem para sobreviver a partir de códigos legais vigentes. Ao mesmo tempo, o parque é visto pelos moradores como um ente externo: "Diz que ele [parque] veio de Brasília, é do governo. Quem faz a lei lá, não conhece a realidade aqui não". Com todos esses elementos, os moradores classificam o parque como algo abstrato: "Ninguém vê o parque, só sabe que ele existe".

Os apanhadores demandaram, e demandam, o reconhecimento e o direito de coleta nos cultivos de sempre-vivas, embora elas tenham sido declaradas em extinção, bem como a criação de normas estatais que reconheçam a atividade e viabilizem sua comercialização. Os técnicos dos órgãos ambientais rebateram a proposta, face à ausência de instrumentos de regularização da situação e comercialização dos produtos. As espécies persistem como ameaçadas de extinção e continuam a deflagrar tensões.

Tal contexto exigiu dos representantes de diversas comunidades atos políticos, bem como a constituição de uma Comissão em Defesa dos Direitos das Comunidades Extrativistas (CODECEX). Eles participaram de formação em direitos civis promovida por uma universidade regional; acionaram os Ministérios Públicos Federal e Estadual e buscaram inserção em redes mais amplas de lutas sociais. Para eles, é imperativo que os direitos previstos por leis federais relativos a povos e comunidades tradicionais os fortaleçam e que os limites da unidade e os direitos de sua categoria sejam revistos, constituindo estratégias cotidianas de resistência em seus lugares de vida. Os "apanhadores de flores" persistem frente às restrições 
impostas pelo parque, num processo contraditório que os submete e os qualifica como sujeitos (THERBORN, 1991) envolvidos diretamente pela expropriação/ação estatal.

Ao mesmo tempo, o termo "preservação" é ressignificado em meio às disputas, como expresso por um morador atingido: "Nós somos a favor da preservação da natureza e fizemos isso a vida inteira, tanto que eles acharam isso aqui bem cuidado e quiseram fazer um parque. A questão é que nós não queremos ser excluídos da preservação". As comunidades constroem seus contra-argumentos a partir dos saberes cunhados em suas vivências e valores (DIEGUES, 2001; BARRETO FILHO, 2004). Elas resistem, lutam contra a expropriação e a exclusão; lutam pela re-apropriação social da natureza (LEFF, 1998). A luta é também pelo direito e conquista de um outro espaço discursivo, com outras visões sociais de mundo, outros sistemas cognitivos, que desafiem a hegemonia da colonização global e o totalitarismo epistêmico da ciência moderna (MAZZETTO, 2006).

\section{CONSIDERAÇÕES FINAIS}

As formas de interação e apropriação da $n a-$ tureza enleiam construções de mundos cujas visões sociais aludem a territorialidades de distintas escalas, disputas e contradições. A visão de mundo hegemônica, em que pesa a força simbólica da ciência moderna e do Estado na contemporaneidade, legitima a distribuição desigual de poder. Na luta social que envolve áreas naturais protegidas, enquanto categorias da modernidade ocidental, desvelam-se contradições que exteriorizam injustiças face às acepções de natureza e meio ambiente. Elas explicitam relações assimétricas de poder na classificação do que é verdadeiro, necessário, certo, justo e ético.

O contexto das UCs de proteção integral que contam com a presença de moradores em seu interior, revela uma concepção fragmentada de natureza ao mesmo tempo em que negligencia/nega o outro. No entanto, para os "apanhadores de flores", esse contexto os alçou à ação política e popular num esforço pela apropriação e manutenção, material e simbólica, de seus territórios, em que a recategorização do parque para reserva extrativista é visto como uma possibilidade. O Estado Democrático de Direito, "mediador legítimo das tensões sociais", é desafiado no âmbito multicultural ou multicivilizacional, pois, ao negar, desterritorializa. Porém, os sujeitos redesenham sua existência e resistência através de identidades atadas à ancestralidade de usos coletivos, manifestam do espaço vivido, contra-espaços politicamente requeridos. $\mathrm{O}$ território torna-se uma relação sujeita a instabilidades, posto que o mundo é reinventado cotidianamente no lugar.

\section{REFERÊNCIAS}

ACSELRAD, H. Conflitos ambientais no Brasil. Rio de Janeiro: Relume Dumará: Fundação Heinrich Böll, 2004.

ALIER, J. M. O ecologismo dos pobres: conflitos ambientais e linguagens de valoração. São Paulo: Contexto, 2007.

ANDERSON, B. Comunidades Imaginadas. Reflexiones sobre el origen y el difusión del nacionalismo. México: Fondo de Cultura Económica, 1991.

BAKHTIN, M. Marxismo e filosofia da linguagem. São Paulo: Hucitec. $6^{a}$ edição, 1992.

BARRETTO FILHO, H. T. Notas para uma história social das áreas de proteção integral no Brasil. In: RICARDO, F. (Org.) Terras Indigenas e Unidades de Conservação. São Paulo: Instituto Socioambiental, 2004, p.53-63.

BEDIM, B. P. O processo de intervenção social do turismo na serra de Ibitipoca (MG): simultâneo e desigual o dilema camponês no "paraíso do capital". Dissertação (Mestrado), 2008. UFMG, Belo Horizonte.

BOURDIEU, P. O poder simbólico. 12a . ed., Rio de Janeiro: Bertrand Brasil, 2009.

BRANDÃO, C. R. Somos as águas puras. Campinas: Papirus, 1994. 
CAMPOS, N.; KRAHL, M.F.L. Territorialidade: elo entre o espaço rural e o espaço urbano. In: STEINBERGER, M (Org.) Território, ambiente e políticas públicas espaciais. Brasília: Paralelo 15 e LGE, 2006, p.83-100.

CHAUÍ, M. O que é ideologia. São Paulo: Brasiliense, 2004.

Cultura e democracia: o discurso competente e outras falas. São Paulo: Cortez, 1982.

CLAVAL, Paul. Espacialidades e representações de mundo. GEOgrafias, Belo Horizonte vol. 5, n.2, 2009, p.6-22. Entrevista concedida a Guilherme da Silva Ribeiro. 1973.

.Príncipes de géographie sociale. Paris: Litec,

CUNHA, M. C. Negros, Estrangeiros: Os escravos libertos e sua volta à África. São Paulo: Brasiliense, 1985.

DAMIANI, A. L. As contradições do espaço: da lógica (formal) à (lógica) dialética, a propósito do espaço. In: DAMIANI, A. L.; CARLOS, A. F. A.; SEABRA, O. C. de L. (Orgs.). O espaço no fim de século: a nova raridade. São Paulo: Contexto, 2001, p. 48-66.

DIEGUES, A. C. O mito moderno da natureza intocada. São Paulo: Hucitec, 2001.

FOLADORI, G.; TAKS, J. Um olhar antropológico sobre a questão ambiental. Mana. Estudos de Antropologia Social. Rio de Janeiro: PPGAS/UFRJ, vol. 10, n. 2, p. 323-348, 2004.

HAESBAERT, R. Dilema de conceitos: espaço-território e contenção territorial. In: SAQUET, M.A. e SPOSITO, E. S. (Org.) Território e territorialidades: teorias, processos e conflitos. São Paulo: Expressão Popular, 2009, p. 95-120.

HARVEY, D. O enigma do capital: e as crises do capitalismo. Trad. João Alexandre Peschanski. São Paulo: Boitempo, 2011.
HEIDRICH, Á. L. Conflitos territoriais na estratégia de preservação da natureza. In: SAQUET, M.A. e SPOSITO, E.S. (Org.) Território e territorialidades: teorias, processos e conflitos. São Paulo: Expressão Popular, 2009, p. 271-290.

HISSA, C. E.V. Território de diálogos possíveis. In: RIBEIRO, M. T. F. E MILANI, C. R. S. (Org.) Compreendendo a complexidade socioespacial contemporânea: o território como categoria de diálogo interdisciplinar. Salvador: EDUFBA, p. 36-84, 2009.

IBAMA. Processo de criação do Parque Nacional das Sempre-vivas. Brasília/DF, 2002, 185p. (Documento).

LEFEBVRE, H. Espaço e política. Belo Horizonte: UFMG, 2008.

La presencia y la ausencia: contribuición a la teoria de las representaciones. Madrid: Morata, 1983.

. O direito à cidade. São Paulo: Documentos, 1969.

LEFF, E. Ecologia, Capital e Cultura: racionalidade ambiental, democracia participativa e desenvolvimento sustentável. Blumenau: FURB, 2000.

. Saber Ambiental: sustentabilidade, racionalidade, complexidade e poder. México: Siglo Veintiuno Editores, 1998.

LITTLE, P. Territórios Sociais e Povos Tradicionais no Brasil: Por uma antropologia da territorialidade. In: Simpósio Natureza e Sociedade: Desafios Epistemológicos e Metodológicos para a Antropologia, 23a Reunião ABA, Gramado, RS. Anais..., ABA, 2002.

LÖWY, M. Ideologias e ciência social. São Paulo: Cortez, 2002.

MARTINS, J. de S. Henri Lefebvre e o retorno à dialética. São Paulo: Hucitec, 1996. 
MAZZETTO, C. E. Os cerrados e a sustentabilidade: territorialidades em tensão. Tese (Doutorado), 2006. UFF, Niterói.

MENDES, A. B. V. Conservação ambiental e direitos multiculturais: reflexões sobre justiça. Tese (doutorado), UNICAMP, Campinas. 2009.

MONTEIRO, F. T. Os(as) apanhadores(as) deflores e o Parque Nacional das Sempre-Vivas (MG): travessias e contradições ambientais. Dissertação (Mestrado), UFMG, Belo Horizonte. 2011.

MUNGAI, M. F. Mosaico de interesses, relações e conflitos: o Parque Nacional Cavernas do Peruaçu (MG). Dissertação (Mestrado), UFMG, Belo Horizonte. 2008.

PÊCHEUX, M. O mecanismo do (des)conhecimento ideológico. In: ZIZEK, S. (Org.) Um mapa da ideologia. Rio de Janeiro: Contraponto, 1996, p. 143-152.

RAFFESTIN, C. Por uma geografia do poder. São Paulo: Ática, 1983.

SAADI, A. A geomorfologia da Serra do Espinhaço em Minas Gerais e de suas margens. Geonomos, Belo Horizonte, vol. 3, n. 1, 1995, p. 41-63.

SANTOS, M. A natureza do espaço: técnica e tempo, razão e emoção. São Paulo: EDUSP, 2002.

SOUSA SANTOS, B. Para além do pensamento abissal: das linhas globais a uma ecologia dos saberes. In: SOUSA SANTOS, B. e MENEZES, M. P. (Org.). Epistemologias do Sul. São Paulo: Cortez, 2010.

SOUZA FILHO, C. F. Mares de. Bens culturais e proteção jurídica. Porto Alegre: Unidade Editorial, 1997.

THERBORN, G. La ideología del poder y el poder de la ideología. México: Siglo Veintiuno, 3ª ed. 1991.

THOMPSON, J. B. Ideologia e cultura moderna. Petrópolis: Vozes, 1989.
UFVJM; PUC-MG; PMD; EMATER-MG; IDENE. Encontro de atores da cadeia do extrativismo vegetal da Serra do Espinhaço. Diamantina/MG, 2009, 46p. (Relatório).

WANDERLEY, M. de N. B. A emergência de uma nova ruralidade nas sociedades modernas avançadas: 0 "rural" como espaço singular e ator coletivo. Estudos Sociedade e Agricultura. Rio de Janeiro: UFRJ, v. 15, p. 69-129, 2001.

WEBER, M. Ciência e política: duas vocações. São Paulo: Cultrix, 2005. 